\title{
Aggrecan Directs Extracellular Matrix-Mediated Neuronal Plasticity
}

\author{
Daire Rowlands, ${ }^{1 \star}{ }^{\circledR}$ Kristian K. Lensj $ø,{ }^{2 *}$ Tovy Dinh, ${ }^{4}$ Sujeong Yang, ${ }^{1}{ }^{\oplus}$ Melissa R. Andrews, ${ }^{3}$ Torkel Hafting, ${ }^{2,4}$ \\ Marianne Fyhn, 2 (D) James W. Fawcett, ${ }^{1,5}$ and (D)Gunnar Dick ${ }^{2}$ \\ ${ }^{1}$ John van Geest Centre for Brain Repair, University of Cambridge, Robinson Way, Cambridge CB2 0PY, United Kingdom, ${ }^{2}$ Department of Biosciences, \\ University of Oslo, 0316 Oslo, Norway, ${ }^{3}$ Biological Sciences, University of Southampton, Southampton SO17 1BJ, United Kingdom, ${ }^{4}$ Institute of Basic \\ Medical Sciences, University of Oslo, 0317 Oslo, Norway, and ${ }^{5}$ Centre for Reconstructive Neuroscience, Institute for Experimental Medicine CAS, Prague, \\ Czech Republic
}

In the adult brain, the extracellular matrix (ECM) influences recovery after injury, susceptibility to mental disorders, and is in general a strong regulator of neuronal plasticity. The proteoglycan aggrecan is a core component of the condensed ECM structures termed perineuronal nets (PNNs), and the specific role of PNNs on neural plasticity remains elusive. Here, we genetically targeted the Acan gene encoding for aggrecan using a novel animal model. This allowed for conditional and targeted loss of aggrecan in vivo, which ablated the PNN structure and caused a shift in the population of parvalbumin-expressing inhibitory interneurons toward a high plasticity state. Selective deletion of the Acan gene in the visual cortex of male adult mice reinstated juvenile ocular dominance plasticity, which was mechanistically identical to critical period plasticity. Brain-wide targeting improved object recognition memory.

Key words: aggrecan; inhibitory; interneuron; neuronal plasticity; parvalbumin; perineuronal nets

\section{Significance Statement}

The study provides the first direct evidence of aggrecan as the main functional constituent and orchestrator of perineuronal nets (PNNs), and that loss of PNNs by aggrecan removal induces a permanent state of critical period-like plasticity. Loss of aggrecan ablates the PNN structure, resulting in invoked juvenile plasticity in the visual cortex and enhanced object recognition memory.

\section{Introduction}

The capability of the brain to adapt and change alters during the life span, decreasing with age. This limited adult brain plasticity is advantageous to stabilize functional neuronal circuits but limits recovery of function after injury. In juvenile animals, immature cortical circuits are particularly malleable at certain stages of development termed critical periods (CPs) when adequate sensory stimuli are necessary to refine cortical circuits into functional

Received May 4, 2018; revised Aug. 31, 2018; accepted Sept. 20, 2018.

D.R., K.K.L., T.D., S.Y., M.R.A., T.H., M.F., J.W.F., and G.D. designed research; D.R., K.K.L., T.D., S.Y., M.R.A., T.H., M.F., and G.D. performed research; M.R.A., J.W.F., and G.D. contributed unpublished reagents/analytic tools; D.R., K.K.L., T.D., S.Y., T.H., and M.F. analyzed data; D.R., K.K.L., M.F., and G.D. wrote the paper.

This work was funded by Alzheimer's Research UK (Grant ARUK-RF2016A-1), the Christopher and Dana Reeve Foundation, the Research Council of Norway (Grants 143543, 143730, and 549217 to M.F.; and 231248 to T.H.), and the University of Oslo. We thank Dr. Connor Quinn for assistance with image analysis, Tove Klungervik and Bård Enger Mathisen for assistance with genotyping, and Rune A. Lanton for technical assistance for imaging of optical intrinsic signals.

${ }^{*} D$.R. and K.K.L. contributed equally to this work.

The authors declare no competing financial interests.

Correspondence should be addressed to Gunnar Dick, Department of Biosciences, University of 0slo, P.O. Box 1066,0316 0slo, Norway. E-mail: gunnar.dick@mn.uio.no.

https://doi.org/10.1523/JNEUROSCl.1122-18.2018

Copyright $\odot 2018$ the authors $\quad 0270-6474 / 18 / 3810102-12 \$ 15.00 / 0$ units. Closure of the CPs and concomitant loss of juvenile plasticity coincide with the maturation of inhibitory circuits (Hensch, 2004) and condensation of extracellular matrix around subtypes of neurons. These perineuronal nets (PNNs) are enriched in chondroitin sulfate (CS) proteoglycans (CSPGs) and associated matrix molecules (Härtig et al., 1994; Deepa et al., 2006). Remarkably, enzymatically degrading the CS glycosaminoglycan (GAG) component (Pizzorusso et al., 2002) or ablating the cross-linking cartilage link protein 1 (Crtl1; Carulli et al., 2010) restores juvenile plasticity in the adult animal and affects memory and learning, as revealed by behavioral tasks such as fear memory extinction (Gogolla et al., 2009) and spontaneous object recognition (SOR; Romberg et al., 2013). However, the identity of the CSPG responsible for these effects has not been determined. Here we investigate the role of the CSPG aggrecan, a major constituent of PNNs, encoded by Acan (Matthews et al., 2002). Aggrecan in PNN formation has only been studied in vitro (Giamanco et al., 2010; Kwok et al., 2010), as mutation in the Acan gene results in embryonic lethality due to the lack of cartilage in the trachea and other critical structures (Rittenhouse et al., 1978). In this study, we developed a conditionally gene-targeted Acan mouse model to 
address the role of aggrecan in PNN formation, plasticity, and memory function in the brain.

\section{Materials and Methods}

Animal housing and ethics. All animal work was performed in accordance with national law and regulation, in Cambridge in accordance with the UK Animals Scientific Procedures Act (1986), and in Oslo by the approval of the Norwegian Animal Research Committee. Animals used in this study were housed in standard housing conditions with a $12 \mathrm{~h}$ light/ dark cycle. Animals were housed in groups of two to five per cage, with the exception of one individual animal. Animals were fed and watered ad libitum.

Generation of Acan-loxP and breeding strategy. Two JM8A3.N1 embryonic stem (ES) cell lines of agouti C57BL/6N origin (Pettitt et al., 2009); mice \#HFP0602_5_G11 and \#HFP0602_5_F12, carrying the targeted Acan gene, were purchased from the European Mouse Mutant Cell Repository (EuMMCR). The two ES cell lines are clones containing the same transgenic cassette surrounding exon 4 of the mouse Acan gene (Fig. 1a) a general "knock-out first" design used by the EUCOMM project, termed transgenic allele tm1a (Skarnes et al., 2011). Genomic DNA from the ES cell lines was analyzed by Southern blotting to confirm correct genetic targeting. ES cells were plated and prepared according to the supplier guidelines before microinjection into 50 blastocysts of albino C57BL/6 $\mathrm{tyr}^{-1-}$ origin and subsequent transfer to three pseudopregnant females per line. The chimeric offspring, hybrid $\mathrm{F}_{1}$ generation, was selected by the appearance of coat color spots originating from transgenic cells. The $\mathrm{F}_{1}$ animals were then crossed with albino C57BL/6J tyr $^{-1-}$ mice, and the transmission of genotype into the $G_{1}$ generation was detected by coat color and verified by PCR genotype analysis using GT3 and wild-type (WT) primers (Table 1), confirming the heterozygote tmcla transgenic animal. The tmia allele is not viable in a homozygous state, as the transgenic cassette interferes with Acan expression. The mouse was further crossed with the ROSA26::FLPe strain expressing FLP-FRT recombinase removing the majority of the transgenic cassette leading to off spring carrying the Cre-lox conditional knock-out allele tm1c (Fig. 1a), designated as the conditional knockout of Acan; B6(Cg)ACAN $^{\text {tmlc(EUCOMM)Hmgu }>/ J w f a}$, hereafter referred to as Acan-loxP. PCR genotype analysis using primer pairs FLP, tmc1, and GT5, confirmed presence of FLP recombinase and presence of $t m 1 c$. The $t m 1 c$ allele is viable as a homozygote. Conditional knockout of Acan is achieved by removing exon 4 of the Acan gene by Cre-lox recombination, resulting in the tmld allele (Fig. 1a). Loss of exon 4 induces a shift in the reading frame, and thereby prevents protein translation.

Brain-wide and developmental Cre-lox recombination by Nestin-CRE. To achieve brain-wide knockout of Acan, Acan-loxP ${ }^{+/+}$was crossed with Nestin-CRE (CreNes), where Cre recombinase is expressed under the control of the promoter and the nervous system-specific enhancer present in the second intron of the rat Nes gene (Tronche et al., 1999). The offspring of Acan-loxP ${ }^{+/-}$CreNes mice were then backcrossed for at least one generation. The offspring of this cross, WT littermates, AcanloxP $\mathrm{P}^{+/+}$, Acan-loxP $^{+/-}$Cre, and Acan-loxP ${ }^{+/+}$Cre, were used for histological analysis and behavioral testing. Again, PCR genotype analysis was conducted using WT, GT3, GT3WT, and CRE primer pairs (Table 1). All of the resulting offspring had a normal phenotype and body size (data not shown). Juvenile animals explored and developed normally and were able to rear and feed themselves (experimenter observations). All genotypes were established using PCR on genomic DNA extracted from an ear punch.

Local and acute Cre-lox recombination by virus and retrograde tracer injection. AAV9.hSyn.HI.eGFP-Cre.WPRE.SV40 (catalog \#AV-9-PV1848) was purchased from the Penn Vector Core (University of Pennsylvania, Philadelphia, PA), and stored at $-80^{\circ} \mathrm{C}$. Before surgery, aliquots were thawed on ice and diluted in filtered $1 \times \mathrm{PBS}$ to a concentration of $10^{13}$ $\mathrm{GC} / \mathrm{ml}$. Adult mice (3-4 months old) of either Acan-loxP $\mathrm{P}^{+/+}$or AcanloxP $\mathrm{P}^{+/-}$genotype were anesthetized with isoflurane mixed with air $(5 \%$ induction, $1.0-1.8 \%$ maintenance) using a Somnosuit vaporizer (Kent Scientific) and a custom-made mask, and were placed on a controllable heating pad in a stereotaxic frame. They were injected subcutaneously with buprenorphine $(0.04 \mathrm{mg} / \mathrm{kg})$ and carprofen $(5 \mathrm{mg} / \mathrm{kg})$, and bupiv- acaine $(13 \mathrm{mg} / \mathrm{kg})$ locally. The scalp was shaved and cleaned with $70 \%$ ethanol and chlorhexidine, and a small incision was made in the skin. A craniotomy (diameter, $1-1.5 \mathrm{~mm}$ ) was performed above the binocular zone of primary visual cortex (V1) using a handheld dental drill. The virus solution was loaded into a glass pipette (opening diameter, $\sim 15$ $\mu \mathrm{m}$ ) and mounted in a Nanoject 3 Microinjector (Drummond Scientific). A total of $500 \mathrm{nl}$ was injected in a stepwise manner over $10 \mathrm{~min}$, and the pipette was left in the tissue for $10 \mathrm{~min}$ before retraction [injection coordinates relative to lambda were: anteroposterior (AP), $0.0 \mathrm{~mm}$; mediolateral (ML), $3.0 \mathrm{~mm}$; dorsoventral (DV), $0.5 \mathrm{~mm}$ ]. The wound was rinsed repeatedly with sterile $0.9 \% \mathrm{NaCl}$ and closed by suture. The animals were observed for at least $1 \mathrm{~h}$ before they were placed back in the colony. Animals were monitored closely for a week following surgery, and were given subcutaneous injections of buprenorphine and carprofen for the first $3 \mathrm{~d}$ after surgery. For retrograde tracing between V1 and the dorsal part of the lateral geniculate nucleus, cholera toxin subunit B conjugated to Alexa Fluor 488/594 was purchased from Life Technologies and a $1 \%$ solution was made by reconstitution in $1 \times$ PBS. Surgical procedures were as described above. The tracer injections were intentionally targeted to a more medial part of V1 to prevent leakage into the neighboring V2L region. A total of $200 \mathrm{nl}$ was injected for each of the tracers at $0.0 \mathrm{~mm} \mathrm{AP,} \mathrm{2.7.0} \pm 0.1 \mathrm{~mm} \mathrm{ML}$, and $0.5 \mathrm{~mm} \mathrm{DV}$, and the injections of each conjugate were separated by $0.2 \mathrm{~mm}$. The wound was cleaned with sterile $0.9 \% \mathrm{NaCl}$ and closed by suture. Medication was administered as described above.

Histology. At the end of the experiment or an appropriate time point, animals were deeply anesthetized by an intraperitoneal injection of sodium pentobarbital $(50 \mathrm{mg} / \mathrm{kg})$ and perfused with either $0.9 \% \mathrm{NaCl}$ [ocular dominance (OD) experiment] or $\mathrm{Na}_{2} \mathrm{HPO}_{4} \cdot 2 \mathrm{H}_{2} \mathrm{O}$ (Acan-loxP CreNes) buffer, followed by $4 \%$ paraformaldehyde (PFA). Brains were dissected out and postfixed in PFA solution overnight and cryoprotected in $30 \%$ sucrose in $1 \times$ PBS for $24 \mathrm{~h}$. Coronal sections of 30 or $40 \mu \mathrm{m}$ were collected from the cryostat or freezing microtome and transferred to $1 \times$ PBS. Sections were rinsed in $1 \times$ PBS and blocked for $1 \mathrm{~h}$ in $2-10 \%$ animal serum (species dependent on secondary antibody host) before primary antibody incubation overnight in blocking solution (Table 2). The following day, sections were rinsed and incubated with secondary antibodies for $2 \mathrm{~h}$. Sections were rinsed and mounted on Superfrost slides with FluorSave Reagent (Merck Millipore).

Following OD testing of AAV9.Cre-injected Acan-loxP ${ }^{+/+}$mice, wide-field fluorescence images were acquired with an AxioPlan 2 Microscope (Zeiss) through a $10 \times$ objective, and high-resolution overview images stitched using the Mosaix extension in the AxioVision Software. Confocal images were acquired using a FluoView FV1000, software version 1.7 (Olympus), through a $20 \times$ or $60 \times$ PlanApo objective. Image analysis was performed using Image $(\mathrm{NIH})$ and Photoshop CS4/6 (Adobe).

For histological quantification of 3- to 4-month-old Acan-loxP $\mathrm{P}^{+/+} \times$ CreNes crosses, images were captured using a Leica SPE confocal microscope using either $10 \times$ or $63 \times$ objectives with a $1024 \times 1024$ image resolution ( $n=3$ /group). For PNN quantification, at least five images per section (three sections per brain, $\sim 300 \mu \mathrm{m}$ apart) were taken on a single confocal plane in layers 4 and 5 of the mouse barrel cortex (Fig. 2). Images contained at least one Wisteria floribunda agglutinin (WFA)labeled PNN (if detected). For Acan-loxP ${ }^{+/+}$CreNes, where no PNNs were detected, representative images were captured randomly in the same region. For parvalbumin (PV) cell analysis by immunohistochemistry at least five $z$-stack images ( 10 stacks, $\sim 3 \mu \mathrm{m}$ apart) were taken per section with at least five sections analyzed per animal ( $\sim 300 \mu \mathrm{m}$ apart). Images were then analyzed with an automated custom script using the EBImage package from R statistical software (Pau et al., 2010). To reduce variance in antibody binding, all groups used for quantification were histologically stained in batches using the same conditions and antibody solutions.

Protein and RNA analysis. For aggrecan protein and gene expression analysis, snap-frozen Acan-loxP ${ }^{+/+}$and CreNes Acan-loxP $\mathrm{P}^{+/+}$brains ( $n=3$ /group) were homogenized over ice, and both protein and RNA were extracted using an AllPrep DNA/RNA/Protein Mini Kit (Qiagen). Before aggrecan protein quantification, $20 \mu \mathrm{g}$ of brain homogenate from 
a

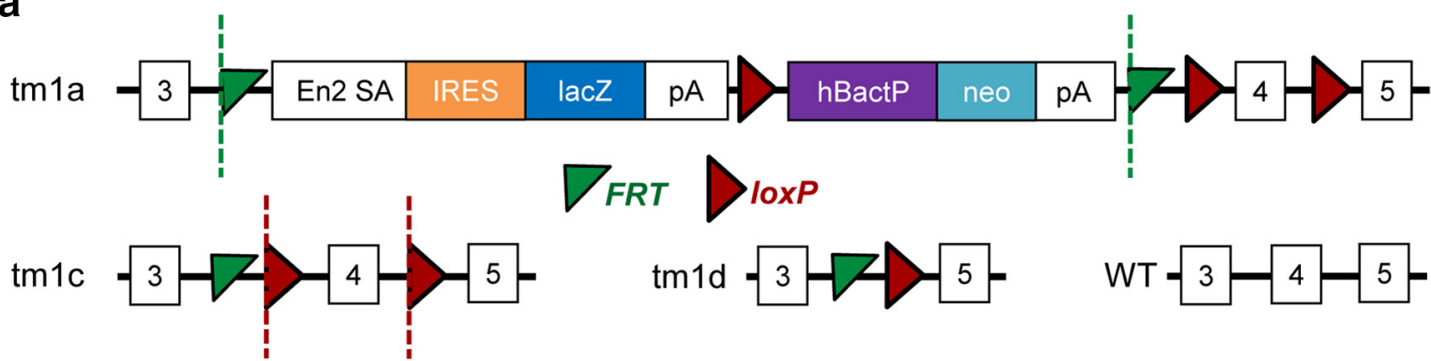

b
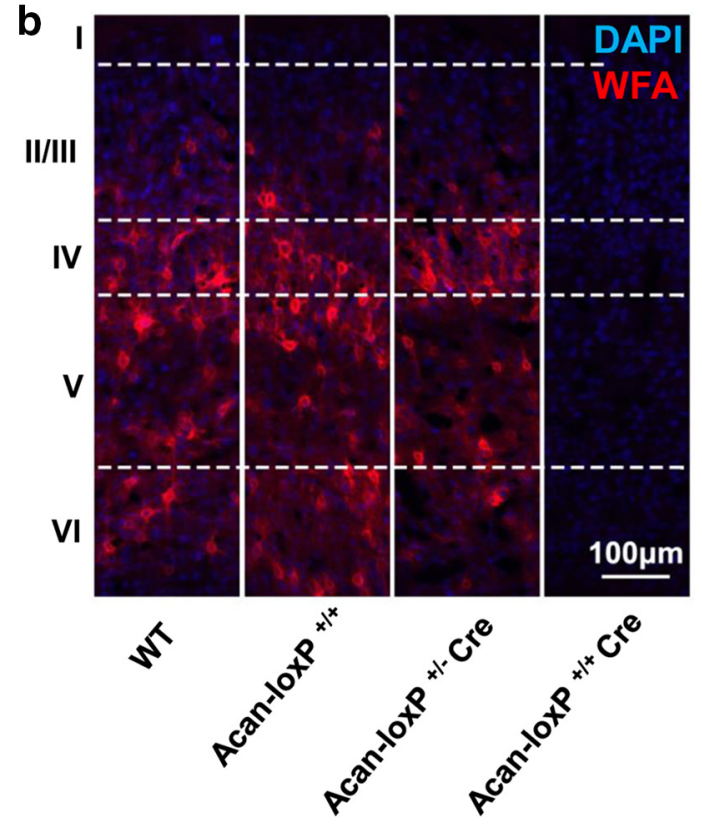

C

\section{$>250 \mathrm{kd}$}

$37 \mathrm{kd}$

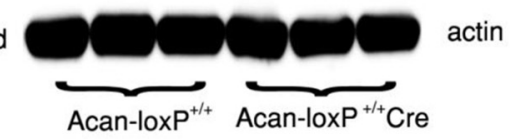

d
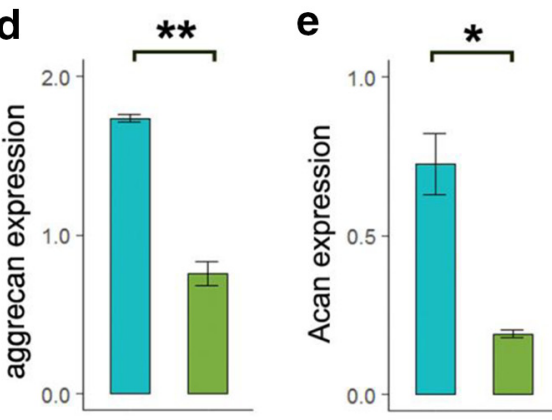

Acan-loxP $\mathrm{P}^{+/}$

Acan-loxP ${ }^{+/+}$Cre

f
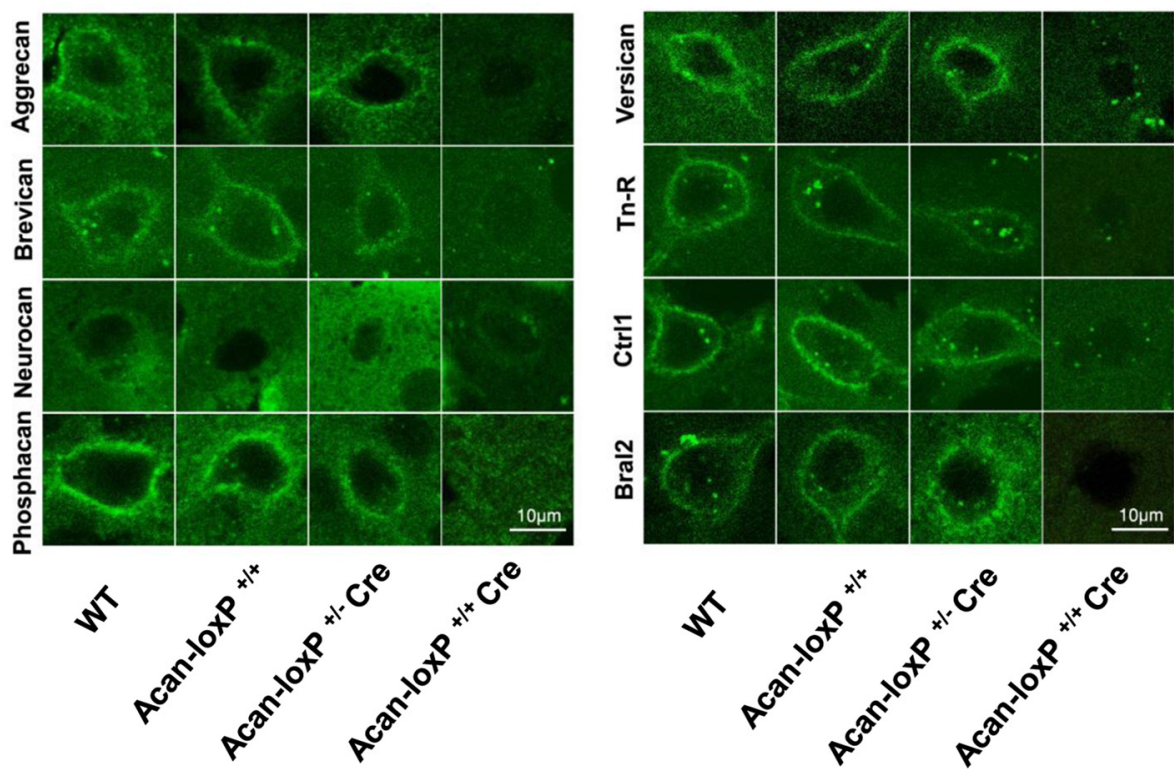

Figure 1. Brain-wide targeting of the Acan gene results in the abolition of WFA-labeled PNNs and individual PNN components. $\boldsymbol{a}$, Schematic representation of the transgenic cassette designed by EuCOMMM: tm1a allele, containing exon 4 of the Acan gene; the subsequent conversion to tm1 c by Flp-FRT recombination; and the knock-out allele tm1 d by Cre-lox recombination. $\boldsymbol{b}$, Representative image of cortical layers 1-6from barrel cortex in WT, transgenic controls (Acan-lox ${ }^{+/+}$), heterozygous Acan knock-out mice (Acan-lox $\mathrm{P}^{+/-}$Cre), and homozygous Acan knock-out mice (Acan-lox $\mathrm{P}^{+/+}$Cre). Sections were stained with WFA (PNN marker, red) and DAPI (nuclear marker, blue), $n=3 /$ group. Scale bar, $100 \mu \mathrm{m}$. WT, Acan-loxP ${ }^{+/+}$and Acan-loxP ${ }^{+/-}$Cre mice appear to have similar numbers and disposition of PNNs, while a complete abolition of PNN staining was observed in Acan-lox ${ }^{+/+}$Cre brains. $c$, Representative examples of Western blot of brain homogenates from Acan-loxP ${ }^{+/+}$and $\mathrm{Acan}-$ lox $\mathrm{P}^{+/+}$Cre mice using the

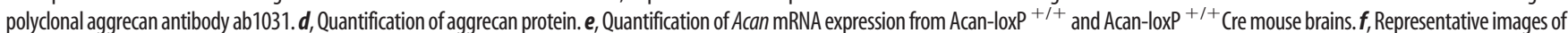
immunohistochemistry of aggrecan, brevican, neurocan, phosphacan, versican, tenascin- $\mathrm{R}(\mathrm{Tn}-\mathrm{R}), \mathrm{Crt} 11$, and brain link protein 2 (Bral2) from WT, Acan-loxP ${ }^{+/+}, \mathrm{Acan}^{-l o x \mathrm{P}^{+/-}} \mathrm{Cre}$, and Acan-loxP ${ }^{+/+} \mathrm{Cre}$ mouse brains. For antibodies, see the tables in Materials and Methods. ${ }^{* *} p<0.01,{ }^{*} p<0.05$. Error bars indicate \pm SEM. 
Table 1. Primers used for genotyping

\begin{tabular}{|c|c|c|c|c|}
\hline Primer set & Forward & Reverse & Annealing temperature (cycles) & Expected band size \\
\hline CRE & 5'-GCAGAACCTGAAGATGTTCGCGAT-3' & 5'-AGGTATCTCTGACCAGAGTCATCC-3' & $62^{\circ} \mathrm{C}(34$ cycles $)$ & $733 \mathrm{bp}$ \\
\hline FLP & 5'-GTCCACTCCCAGGTCCAACTGCAGCCCAAG-3' & $5^{\prime}$-CGCTAAAGAAGTATATGTGCCTACTAACGC- $3^{\prime}$ & $64^{\circ} \mathrm{C}(35$ cycles $)$ & 725 bp \\
\hline $\operatorname{Tm} 1 \mathrm{c}$ & 5'-AAGGCGCATAACGATACCAC-3' & 5'-ACTGATGGCGAGCTCAGACC-3' & $58^{\circ} \mathrm{C}(34$ cycles $)$ & $1055 \mathrm{bp}$ \\
\hline GT3 & 5'-GAGGGCATACAGTCCACCAT-3' & 5'-GTGGTATCGTTATGCGCCTT-3' & $60^{\circ} \mathrm{C}$ (30 cycles) & $613 \mathrm{bp}$ \\
\hline GT3WT & 5'-GAGGGCATACAGTCCACCAT-3' & 5' -CCATCATCAGGCATTCTCCTT-3' & $61^{\circ} \mathrm{C}(30$ cycles $)$ & $613 \mathrm{bp}$ \\
\hline GT5 & $5^{\prime}$-AAGGCGCATAACGATACCAC-3' & $5^{\prime}$-CCGCCTACTGCGACTATAGAGA-3' & $58^{\circ} \mathrm{C}(30$ cycles $)$ & 7092 bp (pre-FLP cross) 218 bp (post-FLP cross) \\
\hline
\end{tabular}

Table 2. Antibodies used to label PNN components and PV + cells

\begin{tabular}{lllll}
\hline Reactivity & Host species & Supplier & Catalog\# & RRID \\
\hline $\begin{array}{l}\text { Primary antibodies } \\
\text { N-acetylgalactosamine }\end{array}$ & n.a. (lectin) & Sigma-Aldrich & L-1516 & AB_2620171 \\
Aggrecan & Rabbit & Merck Millipore & ab1031 & AB_90460 \\
Crtl-1 & Mouse & Merck Millipore & MABT85 & AB_11203324 \\
Crtl-1 & Goat & R\&DSystems & af2608 & AB_2116135 \\
GFP & Chicken & Life Technologies & ab13970 & AB_300798 \\
Neurocan & Sheep & Thermo Fisher Scientific PA5-47779 & AB_2608508 \\
Versican & Rabbit & BosterBio & PB9453 & Not registered \\
Brevican & Mouse & BioLegend & 820101 & AB_2564837 \\
TenascinR & Mouse & R\&DSystems & MAB1624 & AB_2207001 \\
Parvalbumin & Goat & Swant & PVG-214 & AB_2313848 \\
Parvalbumin & Rabbit & Swant & PV27 & AB_2631173 \\
Secondary used in & & & & \\
biotin tagging & & & & \\
Anti-mouse & Goat & Life Technologies & A-24522 & AB_2535991 \\
Anti-goat & Donkey & Abcam & ab6884 & AB_954842 \\
Anti-rabbit & Goat & Life Technologies & 31820 & AB_228340 \\
\hline
\end{tabular}

each sample was deglycosylated with chondroitinase $\mathrm{ABC}(\mathrm{ChABC})$ in PBS with acetic acid (50 U/ml, $\mathrm{pH} 7.8$ ) for $24 \mathrm{~h}$ at $37^{\circ} \mathrm{C}$ to remove $\mathrm{GAG}$ side chains from the aggrecan core protein. Following deglycosylation, samples were subjected to the SDS-PAGE method using a $4-12 \%$ BisTris Mini Gel (NuPAGE, Invitrogen) and Western blotting protein transfer to a PVDF membrane. Membranes were left to air dry before being washed three times with $2 \%$ Triton X-100 in Tris-buffered salineTween 20 (TBS-T). After the final wash, membranes were incubated in a blocking buffer ( $10 \%$ skimmed milk made in TBS-T) for $1 \mathrm{~h}$. After blocking, membranes were then incubated in primary antibodies overnight at $4^{\circ} \mathrm{C}$ with $5 \%$ skimmed milk in TBS-T. The following morning, membranes were washed in triplicate in TBS-T and incubated in secondary antibody for $1 \mathrm{~h}$, after which they were washed again. Proteins were then visualized using the electrochemiluminescence method. Protein quantification was achieved using ImageJ comparing aggrecan signal intensity relative to $\beta$-actin. For aggrecan, all bands $>250 \mathrm{kDa}$ were included for analysis similar to previous studies (Miyata and Kitagawa, 2016), while $\beta$-actin produced a clear band at $37 \mathrm{kDa}$.

For gene expression analysis, mRNA was converted to single-stranded cDNA using a High-Capacity cDNA Reverse Transcription Kit with RNase Inhibitor (Applied Biosystems). Samples were then analyzed using quantitative PCR with inventoried TaqMan probes (Applied Biosystems) for Acan and Actb. A final concentration of $14 \mathrm{ng}$ of cDNA per reaction was used. All samples were run in triplicate and averaged before analysis. Measurements for the expression of Acan were then presented relative to $A c t b$ for graphing and statistical analysis.

Quantification and statistics of the histology signal. Before image processing, a 30\% threshold was applied to the image to eliminate nonspecific binding. Cells whose soma were in the $z$-stack image were extracted, combined intensity values for all pixels in a cell were averaged, and cropped images of $\mathrm{PV}^{+}$ cells were saved for manual verification. The Arbitrary Unit (AU) scale was derived as before based on mean PV values extracted from the WT group.

Assessing OD plasticity in visual cortex using optical imaging of intrinsic signal. Visual stimulus was generated in Matlab using the Psychophysics toolbox, and presented on a $27.5 \times 34 \mathrm{~cm}$ computer monitor (Dell Computers; $60 \mathrm{~Hz}$ refresh rate) placed $25 \mathrm{~cm}$ from the mouse. The stimulus consisted of a thin drifting bar $\left(2^{\circ}\right.$ wide) moving up or down with temporal frequency of $0.17 \mathrm{~Hz}$ and spatial frequency of 0.05 cycles $/^{\circ}$. The stimulus was repeated 20 times, with each presentation interleaved with a gray blank screen. The duration of each recording was $120 \mathrm{~s}$. Stimulus was restricted to the binocular field of vision $\left(20^{\circ}\right)$, with an offset of $5^{\circ}$ toward the respective open eye.

Eight to 10 weeks after virus injection, the animals were prepared for imaging. The experimenter performing imaging experiments and analysis was blind to treatment group and genotype. A custom steel plate for head fixation was attached to the skull using cyanoacrylate and dental acrylic, leaving the area above the visual cortex open. This was covered by a thin layer of nitrocellulose (New-Skin) to prevent desiccation and reactive cell growth.

After head plate implantation, the first imaging of intrinsic signals was performed to measure baseline responses through each eye. Repeated optical imaging of intrinsic signals was performed as described previously (Kaneko et al., 2008). The mouse was anesthetized with isoflurane ( $2 \%$ for induction and $0.5 \%$ during recording) supplemented with an intramuscular injection of chlorprothixene ( $2 \mathrm{mg} / \mathrm{kg}$ body weight). The mice were head fixed and placed on a heating pad in front of the computer monitor, and images were recorded transcranially by a Dalsa M30P Camera (Teledyne) using two adjacently mounted Nikon $50 \mathrm{~mm}$ f/1.2 lenses, and custom Matlab software. Light was provided by LED lights mounted in a ring surrounding the camera lens. Two $525 \mathrm{~nm}$ LEDs were used to focus on the surface blood vessels before focus was shifted 600 $\mu \mathrm{m}$ below the surface. The light source was switched to three $615 \mathrm{~nm}$ LED lights (XPEBRO-L1-R250-00B02, Cree), and emission light was filtered with a red interference filter $(610 \pm 10 \mathrm{~nm})$. Images were acquired with a frame rate of 30 frames per second. The phase and amplitude of cortical responses at the stimulus frequency were extracted by Fourier analysis, as described previously (Kalatsky and Stryker, 2003). The responses to the stimulation of each of the eyes were recorded for four to six trials, alternating between which eye was covered. The median of the peak response amplitude $(R)$ of all trials for each eye were used to calculate an OD index (ODI) by ODI $=\left(R^{\text {contra }}-R^{\text {ipsi }} / R^{\text {contra }}+R^{\text {ipsi }}\right)$.

Immediately after baseline imaging, the eyelids to the contralateral eye was sutured shut. Lidocaine was applied to the sutured area, and the animal returned to its home cage. After $4 \mathrm{~d}$, the mice were again anesthetized, the closed eyelid was reopened, and the imaging procedure was repeated as described above.

Assessing memory by spontaneous object recognition behavioral task. To gauge the memory ability of Acan-loxP ${ }^{+/+}$Cre mice, an SOR behavioral task was used. During testing, male mice ( $n=>7$ per group, $\sim 3$ months old) were placed individually in a Y-shaped maze ( $30 \mathrm{~cm}$ high, all arms 16 $\mathrm{cm}$ in length and $8 \mathrm{~cm}$ wide) as previously described (Romberg et al., 2013). Briefly, animals were habituated to the testing arena, where animals were allowed to explore freely for $5 \mathrm{~min}$ each day, for 2 consecutive days before testing. Each testing session occurred during the dark phase and consisted of a sample phase and a choice phase, using the same objects as in the study by Romberg et al. (2013). During the sample phase, a mouse was placed in the start arm of the maze with sample objects (two identical objects) placed in the two remaining arms and left to explore the objects freely for $5 \mathrm{~min}$. After a 3 or $24 \mathrm{~h}$ delay, animals were returned to the maze for the choice phase. During the choice phase, two new objects were placed in the sample arms, one that is the same as the sample objects (familiar object) and one that was new to the mouse (novel object). For each delay time, mice underwent at least one testing session. All testing sessions were separated by a minimum of $48 \mathrm{~h}$ to allow recuperation. The presentation of the object pairs and their appearance in either the left or right sample arm were counterbalanced so that a particular object in a set 
a
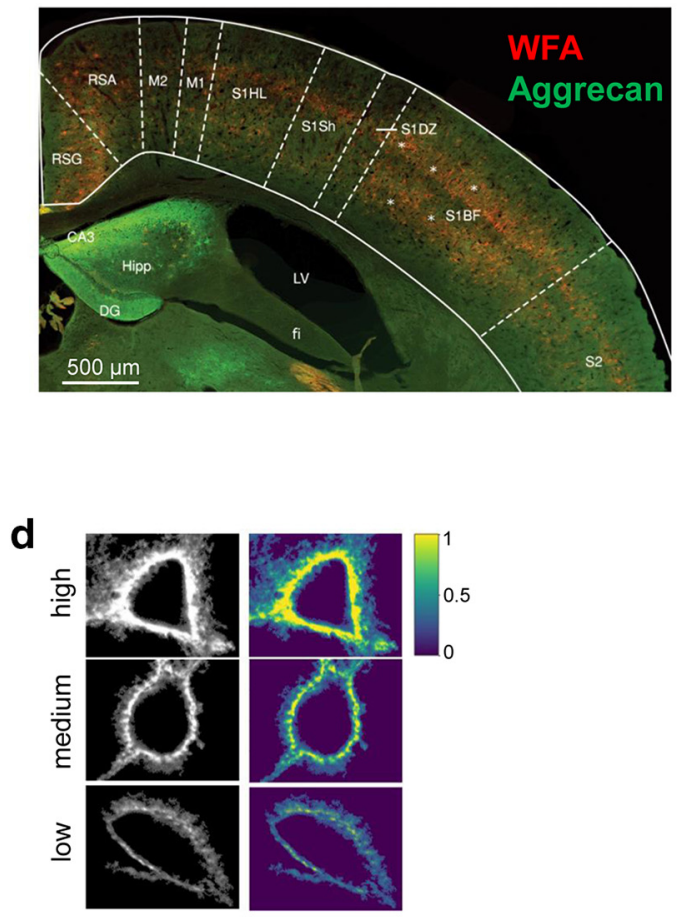

f

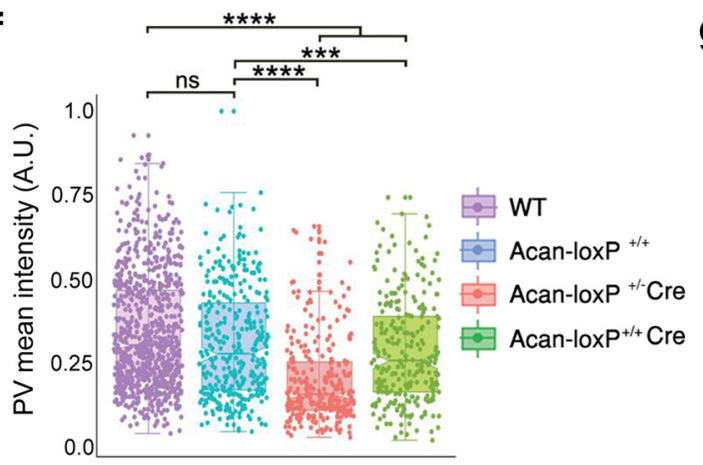

b

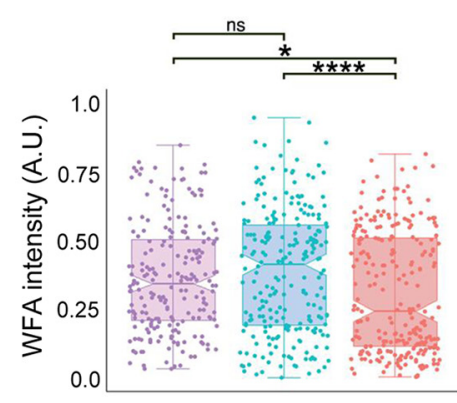

C

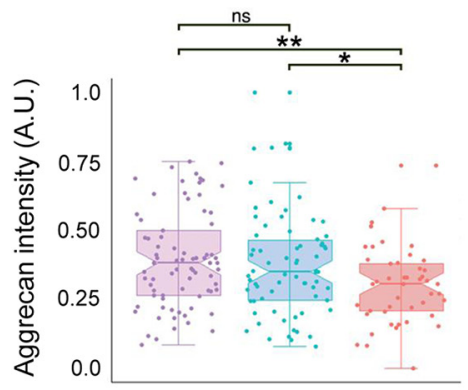

WT

Acan-loxP ${ }^{+/+}$

Acan-loxP ${ }^{+/-}$Cre

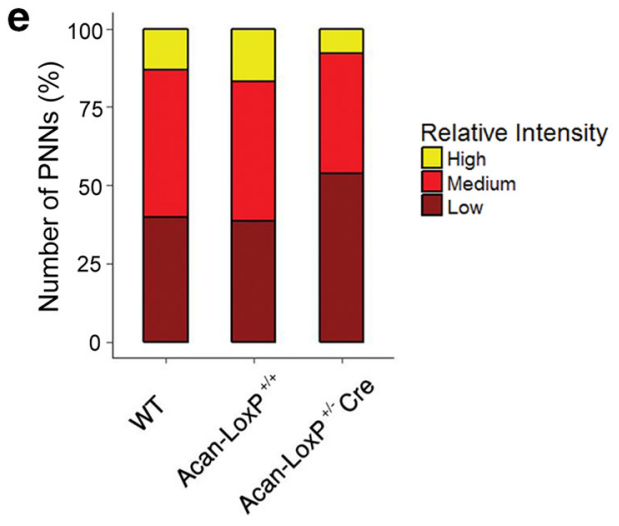

g

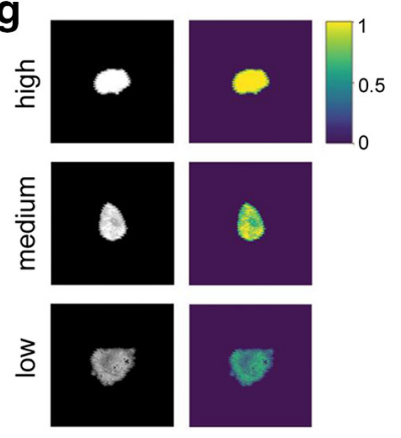

h

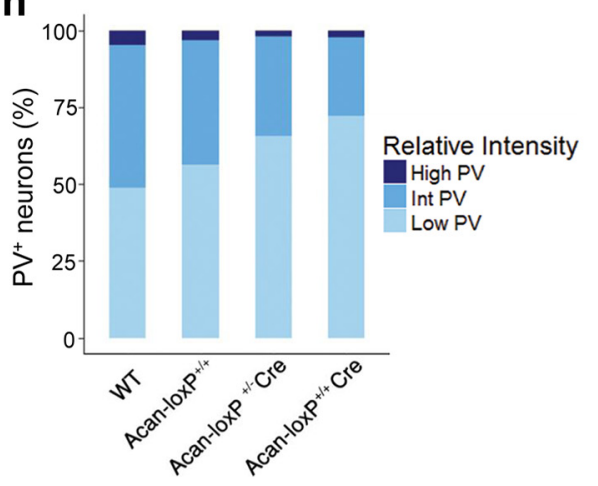

Figure 2. Partial and total removal of aggrecan affects PNN and PV interneuron properties. $\boldsymbol{a}$, Coronal brain section from a wild-type mouse showing the approximate locations in the barrel cortex used for histological sampling (labeled by *). Section stained with the perineuronal net marker WFA (red) and aggrecan (ab1031, green). Scale bar, $500 \mu \mathrm{m}$. $\boldsymbol{b}-\boldsymbol{e}$, Mean intensity values of WFA ${ }^{+}$ (b) or aggrecan ${ }^{+}$(c) PNNs in the cortex of WT (purple), Acan-loxP ${ }^{+/+}$(blue), and Acan-loxP ${ }^{+/-}$Cre (red) mice (d, e) were extracted and analyzed. Acan-lox $\mathrm{P}^{+/-}$Cre displayed a significant reduction in average WFA intensity and aggrecan intensity compared with WT and Acan-lox $\mathrm{P}^{+/+}$controls. $f$, Mean intensity values of $\mathrm{PV}^{+}$neurons in the cortex of WT (purple), Acan-loxP ${ }^{+/+}$

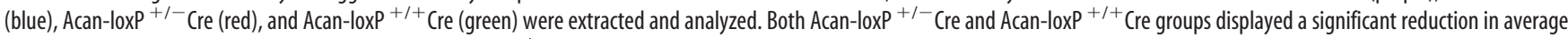
mean intensity per $\mathrm{PV}^{+}$cell compared with WT and Acan-loxP ${ }^{+/+}$controls. The same cortical locations were used for PV histological sampling, as depicted for WFA and aggrecan in $\boldsymbol{a . g}$, Examples of high-, medium-, and low-expressing PV neurons. $\boldsymbol{h}$, Categorization of individual cells based on mean PV intensity indicated a shift toward a low-PV network configuration in the Acan-loxP ${ }^{+/}$Cre and Acan-loxP ${ }^{+/+}$Cre groups compared with controls. ${ }^{*} p<0.05,{ }^{* *} p<0.01,{ }^{* * *} p<0.001,{ }^{* * * *} p<0.0001$.

or a particular side might be novel for one animal and not for another to avoid unforeseen bias. The maze and all objects were wiped down with $70 \%$ EtOH in between each testing session to avoid any olfactory bias that could have been introduced during the previous testing session. Time spent exploring each object during the sample and choice phase was assessed and scored at a later date using the video recordings. A discrimination score was calculated for the choice phase by subtracting the amount of time exploring the familiar object from the amount of time exploring the novel object and then dividing by the total exploration time, as follows:

Time exploring novel - Time exploring familiar Time exploring novel + Time exploring familiar
A positive score indicates recognition of the novel object, while a score of $\leq 0$ indicates the mouse was unable to recognize the novel object. An average was taken for the total sample times per object and the discrimination scores for the choice per time delay.

Experimental design and statistical analysis. Statistical analysis was performed using R (R Foundation) or GraphPad Prism version 7 (GraphPad Software). Datasets were tested for normality using the Shapiro-Wilk test or Fisher's $F$ test. Comparisons between two groups were tested by Welch's $t$ test or paired $t$ test. Multiple group analysis was achieved using a type 1 or type 3 ANOVA with the appropriate follow-up test, either post hoc Tukey's HSD or comparing two groups by Welch's $t$ test. 
Table 3. Statistical analysis biochemical quantification

\begin{tabular}{lrlll}
\hline & \multicolumn{1}{c}{$t$} & $\mathrm{df}$ & $p$ value & Mean of $x$, mean of $y$ \\
\hline Ab1031 WB & 11.365 & 2.7346 & $0.002216^{* *}$ & $1.7059754,0.7572072$ \\
qPCR & 5.501 & 2.0556 & $0.02963^{*}$ & $0.7260774,0.1914709$ \\
\hline
\end{tabular}

Welch's two-sample $t$ test: ${ }^{*} p=0.05 ;{ }^{* *} p=0.01$.

Biochemical quantification of aggrecan protein and the Acan transcript were conducted as described in the Protein and RNA analysis section above. Separate brain homogenates from three male animals, 3-4 months of age from litters originating from the same breeding pair, belonging to each of the two experimental groups, Acan-loxP ${ }^{(+/+)}$and Acan-loxP ${ }^{(+/+)} \mathrm{Cre}$, were analyzed. For protein quantification, ImageJ was used to quantify the aggrecan signal, which was normalized to $\beta$-actin signal, with each lane corresponding to an individual animal (Fig. $1 d$ ). For mRNA quantification, triplicates of $14 \mathrm{ng}$ of cDNA derived from each of the individual animals were run with TaqMan probes against $A c a n$ and $A c t b$, and the relative signal was quantified by the accompanying software (Fig. 1e). The two experimental groups were compared and tested in a Welch's $t$ test (Table 3).

Quantification of PNN intensity by WFA and aggrecan immunohistochemistry were conducted as described in the Histology paragraph above. There were three male animals of 3-4 months of age originating from the same lines of breeding in each of the three experimental groups, WT, Acan-loxP ${ }^{(+/)}$, and Acan-loxP ${ }^{(+/-)}$Cre. At least five images from each of three sections from each brain of the individual animals were analyzed. Images were analyzed with an automated custom script using the EBImage package from R statistical software (Pau et al., 2010). For each experimental group, $>150$ and 50 PNN structures, respectively, were quantified by WFA and aggrecan histochemistry. Each PNN structure is represented as a dot in Figure 2, $b$ and $c$. The three experimental groups were tested in one-way ANOVA with a Tukey's HSD post hoc test (Table 4).

Quantification of PV intensity by PV immunohistochemistry was conducted as described in the Histology section above. There were three male animals of 3-4 months of age originating from same lines of breeding, in each of the four experimental groups: WT, Acan-loxP ${ }^{(+/+)}$, AcanloxP ${ }^{(+/-)}$Cre, and Acan-loxP ${ }^{(+/+)}$Cre. Five $z$-stack images, each consisting of 10 individual images $3 \mu \mathrm{m}$ apart, were taken from each of five sections from each brain of the individual animals and analyzed. Images were analyzed with an automated custom script using the EBImage package from $\mathrm{R}$ statistical software (Pau et al., 2010). More than 150 $\mathrm{PV}^{+}$cells were quantified for each experimental group and represented as a dot in Figure $2 f$. The four experimental groups were tested in oneway ANOVA with a Tukey's HSD post hoc test (Table 5).

Quantification of PNN intensity by WFA after local removal of Acan was conducted as described in the Histology section above. There were six male animals (3-4 months of age) originating from different litters but from the same breeding pair in which each of the two hemispheres contributed to two experimental groups: contralateral control and AAV9.Cre-injected hemispheres. Three sections from each of the individual animals were imaged. Each of the hemispheres of the individual animals is represented as a dot in Figure $3 c$. The two experimental groups were tested in a paired $t$ test. Results are stated in the legend of Figure 3.

Assessing OD plasticity was conducted, as described in the Assessing OD plasticity section, in visual cortex using optical imaging of intrinsic signal section above. There were four, three, and seven male animals 5-7 months of age originating from the same line two breeding pairs and some from the same litters in the three different experimental groups, Acan-loxP $\mathrm{P}^{(+/+)}$untreated, Acan-loxP ${ }^{(+/-)}$AAV9.Cre injected, and Acan-loxP ${ }^{(+/+)}$AAV9.Cre injected. Responses to visual stimuli by each of the two eyes were recorded in four to six trials per eye. Each trial consisted of 20 repetitions of a visual stimulus of $120 \mathrm{~s}$ with simultaneous imaging of the cortex. Initially, baseline responses by the two individual eyes and corresponding ODI for all animals were determined (Fig. $1 c-e$, filled colored circles indicate population means, open gray circles indicate individual animals). After monocular deprivation (MD) of $4 \mathrm{~d}$, the trials were repeated. Eye responses and ODI are represented in similar fashion. A shift in eye responses and ODI induced by MD of $4 \mathrm{~d}$ were tested in a paired $t$ test within the three experimental groups or with Wilcoxon signed rank test whether the distribution was not normal. Results are stated in the legend of Figure 4.

Assessing memory of spontaneous object recognition was conducted as described in the Assessing memory by spontaneous object recognition behavioral task section above. There were 7, 9 ( 1 of which was singly housed), 10 , and 7 male animals $\sim 3$ months of age, respectively, originating from the same line of breeding in each of the four experimental groups, WT, Acan-loxP ${ }^{(+/)}$, Acan-loxP ${ }^{(+/)}$Cre, and Acan-loxP $\mathrm{P}^{(++)}$ Cre. Average exploration times for all experiments in each of the experimental groups varied between 40 and $50 \mathrm{~s}$ (Fig. 5b). To assess differences in the ability to retain memory (Fig. $5 c$ ), ANOVA was used to compare variances between the groups before engaging in post hoc analysis. A significant difference was found in the time point variable, which then justified the exploration of the time point differences within groups and reduced the likelihood that significant values were reached through chance (Table 6).

\section{Results}

This mouse model was established by acquiring JM8A3.N1 ES cells (Pettitt et al., 2009) carrying the "knockout-first" conditional tm1a (Fig. 1a) from the EuMMCR (Skarnes et al., 2011). The initial strain was subsequently converted to $\mathrm{B} 6(\mathrm{Cg})$ $\mathrm{ACAN}^{\mathrm{tm} l \mathrm{c}(\mathrm{EUCOMM}) \mathrm{Hmgu}>/ \mathrm{Jwfa}}$, hereafter referred to as AcanloxP, where Cre recombinase induces an exon deletion and a frame-shift mutation in Acan (Fig. 1a).

Brain-wide targeting of Acan was achieved by crossing AcanloxP with CreNes, where Cre recombinase is expressed under the control of the promoter and the nervous system-specific enhancer present in the second intron of the rat Nes gene (Tronche et al., 1999).

Targeting aggrecan in the brain of Acan-loxP ${ }^{+/+}$CreNes mice was accompanied by a complete loss of histochemical staining of PNNs in the cortex using the PNN marker WFA (Fig. 1b). Ablation of aggrecan was verified by immunohistochemistry and Western blotting (Fig. 1c,d) and reduced Acan mRNA in the brain (Fig. 1e). In these animals, PNNs detected by WFA were absent in the brain. The loss of aggrecan prevented aggregation of other PNN component ECM molecules into PNNs, effectively abolishing PNNs in the adult cortex (Fig. $1 f$, representative example from $>50$ images per PNN component, Fig. $2 a$, overview of sampling). In contrast, the nontargeted Acan-loxP ${ }^{+/+}$mice with two intact alleles expressing Acan, and the targeted heterozygous Acan-loxP ${ }^{+/-}$CreNes mice having one intact allele, both had anatomically normal PNNs (Fig. $1 b, f$ ), although the intensity of the WFA staining was reduced in the heterozygote (Fig. $2 b-e$ ). The crucial dependence of aggrecan for PNN formation is in line with previous results from in vitro models, demonstrating that aggrecan, link protein, and hyaluronic acid are essential components of net formation and stability (Giamanco et al., 2010; Kwok et al., 2010). In contrast, knockout of the link protein Ctrll has been shown to give only a partial reduction of $\mathrm{WFA}^{+}$PNNs (Carulli et al., 2010).

A shift in the distribution of WFA histochemical labeling intensity has been suggested to correlate with the degree of neuronal plasticity in learning and memory (Balmer et al., 2009). Recently, PV expression on GABAergic interneurons has been shown to be influenced by PNNs in the hippocampus (Yamada et al., 2015), and the differentiation state and activity of $\mathrm{PV}^{+}$interneurons relate to learning and memory formation (Donato et al., 2013). To assess whether the reduction or complete lack of aggrecan affects the local PV expression, $z$-stacked images were acquired, and mean PV intensities of neurons in somatosensory 
Table 4. Statistical analysis quantification of PNN intensity

\begin{tabular}{|c|c|c|c|c|c|c|}
\hline & df & Sum squared error & Mean & ed error & Fvalue & $\operatorname{Pr}(>F)$ \\
\hline \multicolumn{7}{|l|}{ ANOVA-WFA } \\
\hline Group & 2 & 0.234 & \multirow{2}{*}{\multicolumn{2}{|c|}{$\begin{array}{l}0.1170 \\
0.0139\end{array}$}} & \multirow[t]{2}{*}{8.419} & \multirow[t]{2}{*}{$0.000244^{* * *}$} \\
\hline \multirow[t]{2}{*}{ Residuals } & 695 & 9.660 & & & & \\
\hline & & & Diff & Lwr & Upr & Adjusted $p$ value \\
\hline \multicolumn{7}{|c|}{ Tukey multiple comparisons of means-WFA 95\% familywise confidence level } \\
\hline tghetcre-tg & & & -0.04293423 & -0.06804163 & -0.01782683 & 0.0001934 \\
\hline wt-tg & & & -0.01396332 & -0.04019866 & 0.01227202 & 0.4241323 \\
\hline \multirow[t]{2}{*}{ wt-tghetcre } & & & 0.02897091 & 0.00310826 & 0.05483356 & 0.0236190 \\
\hline & df & Sum squared error & \multicolumn{2}{|c|}{ Mean squared error } & Fvalue & $\operatorname{Pr}(>F)$ \\
\hline \multicolumn{7}{|l|}{ ANOVA-Aggrecan } \\
\hline Group & 2 & 0.082 & \multirow{2}{*}{\multicolumn{2}{|c|}{$\begin{array}{l}0.04100 \\
0.00877\end{array}$}} & 4.676 & \multirow[t]{2}{*}{$0.0104^{3}$} \\
\hline \multirow[t]{2}{*}{ Residuals } & 192 & 1.683 & & & & \\
\hline & & & Diff & Lwr & Upr & Adjusted $p$ value \\
\hline \multicolumn{7}{|c|}{ Tukey multiple comparisons of means-Aggrecan $95 \%$ familywise confidence level } \\
\hline tghetcre-tg & & & -0.041990928 & -0.08357968 & -0.0004021726 & $0.0472421^{*}$ \\
\hline wt-tg & & & 0.009533334 & -0.02685560 & 0.0459222690 & 0.8100014 \\
\hline wt-tghetcre & & & 0.051524262 & 0.01058598 & 0.0924625400 & $0.0092913^{* *}$ \\
\hline
\end{tabular}

Table 5. Statistical analysis quantification of PV

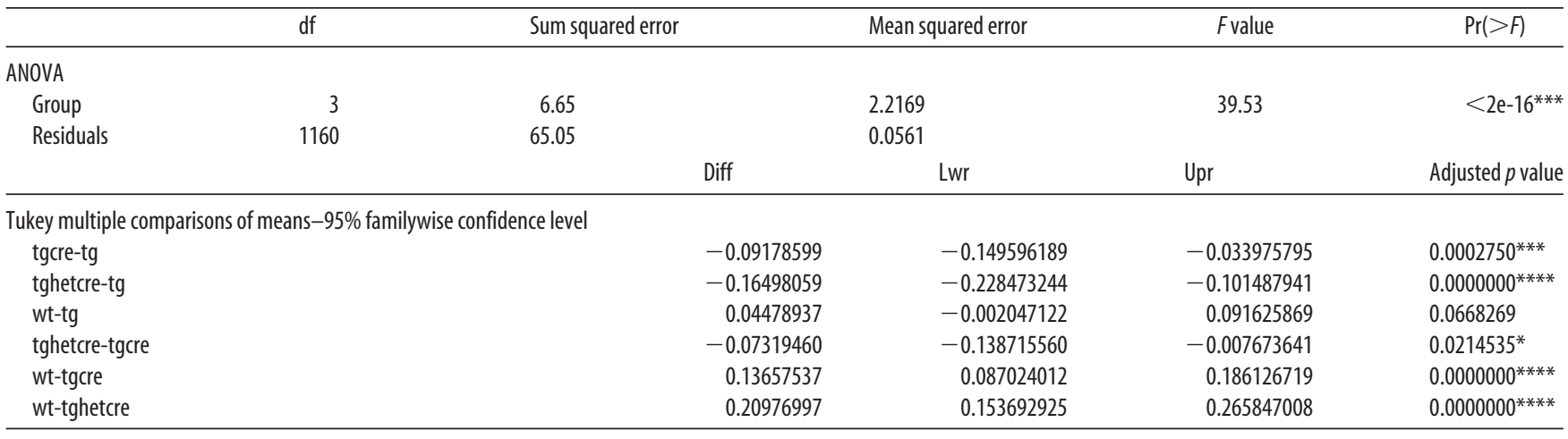

Diff $=$ Difference between means, Lwr $=$ Lower end point $95 \%$ conf. interv., Upr $=$ Upper end point $95 \%$ conf. interv. ${ }^{*} p=0.05 ;{ }^{* * *} p=0.001 ;{ }^{* * *} p=0.0001$.

cortex were extracted ( $>150$ cells/group, three to six sections per group). In both the heterozygous Acan-loxP ${ }^{+/-}$CreNes mice and homozygous Acan-loxP ${ }^{+/+}$CreNes mice, there was a shift toward lower PV expression by $\mathrm{PV}^{+}$interneurons in the cortex compared with wild-type and Acan-loxP ${ }^{+/+}$controls (Fig. 2f-h), indicating that even partial attenuation of the Acan gene induces a low-PV state. This suggests that Acan-loxP ${ }^{+/+}$-CreNes mice are in a state of high network plasticity.

To investigate the effect of locally removing aggrecan in the adult mouse brain, Acan was targeted by injecting the viral vector AAV9.hSyn.HI.eGFP.WPRE.SV40 (AAV9.Cre) carrying Cre recombinase into the V1 (Fig. $3 a$ ). The synapsin promoter restricted expression to neurons. Local injections of AAV9.Cre in adult Acan-loxP $\mathrm{P}^{+/+}$mice caused a complete loss of aggrecan and WFA labeling in V1 8 weeks after virus injection (Fig. $3 b, c$ ). The combined expression of GFP and Cre by the virus revealed loss of PNNs surrounding infected neurons, demonstrating that the expression of aggrecan by neurons is needed to form the PNN structure. Again, loss of aggrecan disrupted the aggregation of the other PNN components (Fig. 3e), suggesting that aggrecan is essential for sustaining PNNs in the visual cortex. Together, these targeting experiments demonstrate an essential role for aggrecan in PNN formation.

PNNs have been implicated in limiting adult brain plasticity due to their CS content (Pizzorusso et al., 2002; Miyata et al.,
2012), enclosing mesh structure (Carulli et al., 2010), ability to bind and sequester active molecules (Beurdeley et al., 2012; Dick et al., 2013), and role in controlling (Kwok et al., 2011) the activity of fast-spiking PV positive neurons (Balmer, 2016; Lensjø et al., 2017). Although several PNN CSPGs have been linked to plasticity regulation, the role of aggrecan, the backbone of PNN remains to be investigated, and a full picture of plasticity regulation is lacking. Activity-dependent plasticity was assessed by inducing OD plasticity in the binocular region of $\mathrm{V} 1$ of adult mice using MD. Tracing of the connections between the lateral geniculate nucleus and $\mathrm{V} 1$ revealed normal retinotopic connectivity between V1 and lateral geniculate nucleus in the thalamus in the nontargeted Acan-loxP $\mathrm{P}^{+/+}$animal (Fig. 4a). Visual responses before and after MD were recorded using optical imaging of intrinsic signals (Fig. 4b), and all groups displayed robust responses to visual stimuli (more than two times the response compared with during gray screen presentations) before MD (Fig. $4 d$, "baseline"). Strikingly, $4 \mathrm{~d}$ of MD were sufficient to produce a strong and significant shift in OD in adult AAV9.Cre-injected AcanloxP $\mathrm{P}^{+1+}$ mice, while no effect was observed in AAV9.Creinjected Acan-loxP ${ }^{+/-}$mice or noninjected Acan-loxP ${ }^{+/+}$mice (Fig. 4c). Longer lasting sensory deprivation has been shown to induce some OD plasticity also in adult mice, but the mechanism differs from juvenile plasticity (Sawtell et al., 2003; Ranson et al., 2012). To determine whether PNN removal caused enhanced 
a

$\begin{array}{|cc|}\begin{array}{c}\text { Virus } \\ \text { injection }\end{array} & \begin{array}{c}\text { Perfusion, } \\ \text { histology }\end{array} \\ \text { PO P90- } & \begin{array}{c}60-90 \\ \text { P120 }\end{array} \\ \text { days }\end{array}$

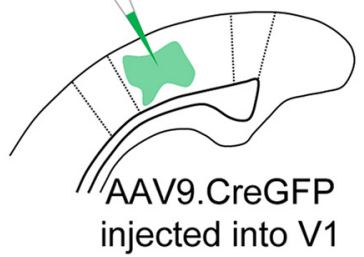

injected into $\mathrm{V} 1$ b
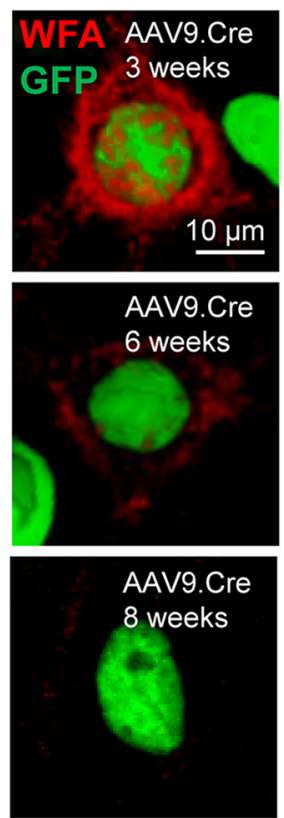

C
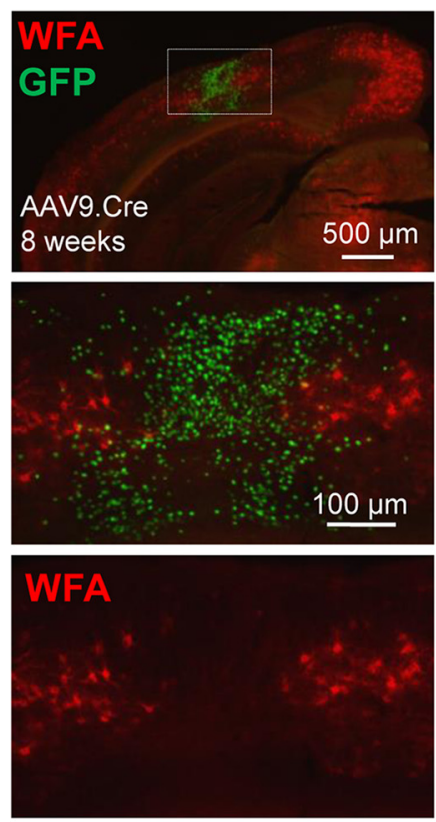

AAV9.Cre treated hemisphere

d Untreated hemisphere

\begin{tabular}{l} 
DAPI \\
Aggregarl \\
GFP \\
\\
$50 \mu \mathrm{m}$ \\
\hline
\end{tabular}
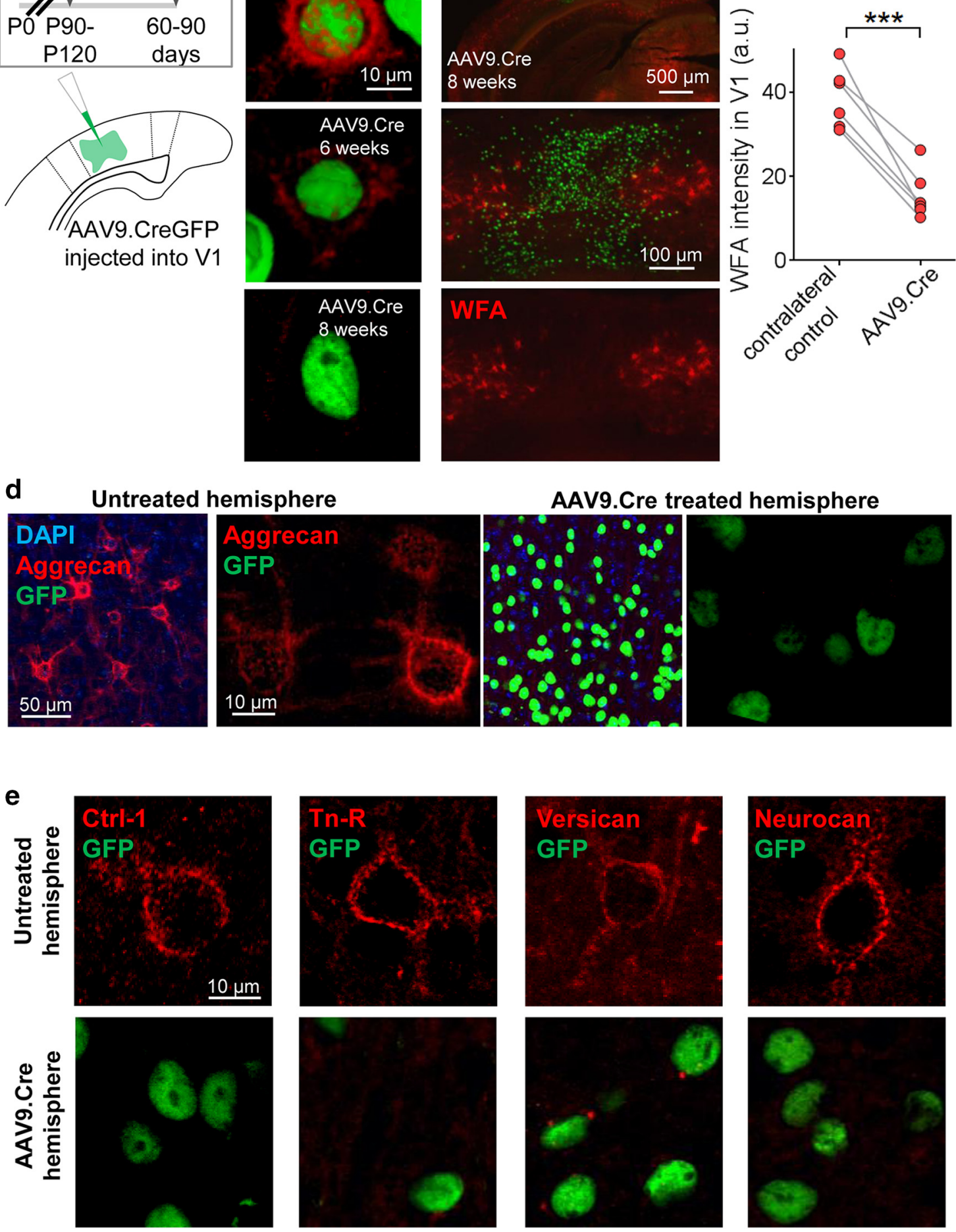

Figure 3. Targeted knockout of Acan in visual cortex of adult mice disintegrates PNNs. $\boldsymbol{a}$, Experimental time line and schematic illustration indicating the injection of AAV9.CreGFP (AAV9.Cre) in V1 of Acan-loxP ${ }^{+/+}$mice. $\boldsymbol{b}, \boldsymbol{c}$, WFA-labeled PNNs gradually disappear over time within the AAV9. Cre-treated area. Sections were costained for GFP to identify transfected neurons. Three weeks after injection, the transfected neurons produced the GFP-Cre fusion protein. After 8 weeks, all PNNs in the injected area in V1 were abolished. Fluorescence intensity measurements of WFA staining were significantly lower in the AAV9.Cre-treated area compared with the corresponding area in the contralateral untreated hemisphere, $p=$ 0.0006 (paired $t$ test, $n=6$ mice), ${ }^{* * *} p<0.001$. Measurements were performed across all cortical layers and averaged from three sections for each animal. $\boldsymbol{d}, \boldsymbol{e}$, Representative confocal images from AAV9.Cre-treated area within V1 and the corresponding area in the contralateral untreated hemisphere from the same section. Local knockout of Acan in V1 removed staining for aggrecan as well as Crtl-1, tenascin-R, versican, and neurocan. 
a

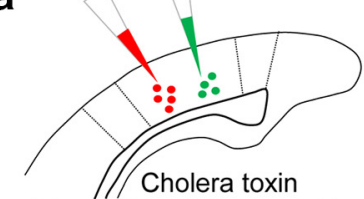

(Alexa 488+594) injected into $\mathrm{V} 1$ of Acan-lox $\mathrm{P}^{+/+}$mice

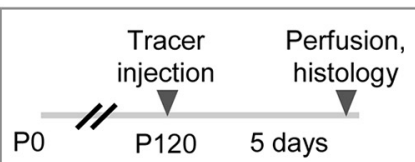

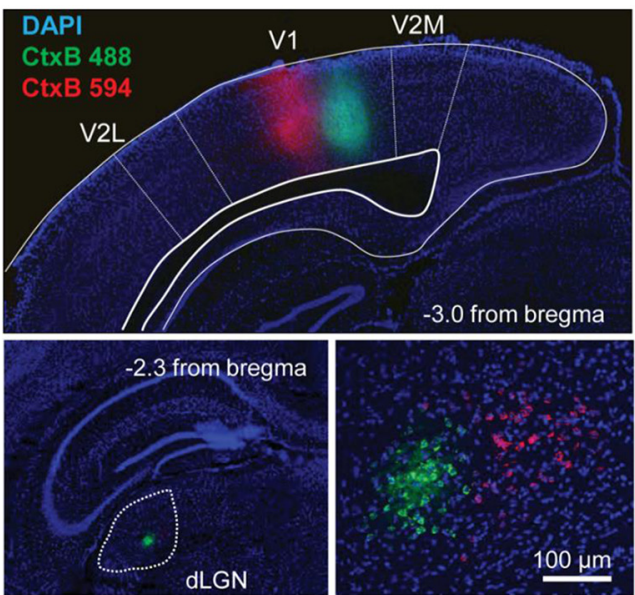

b
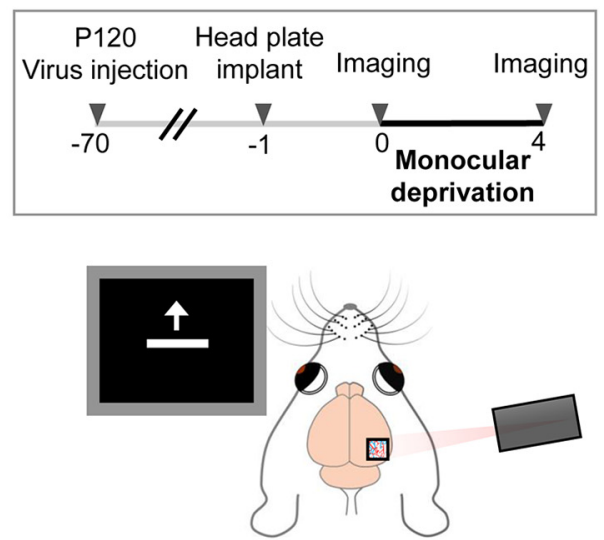

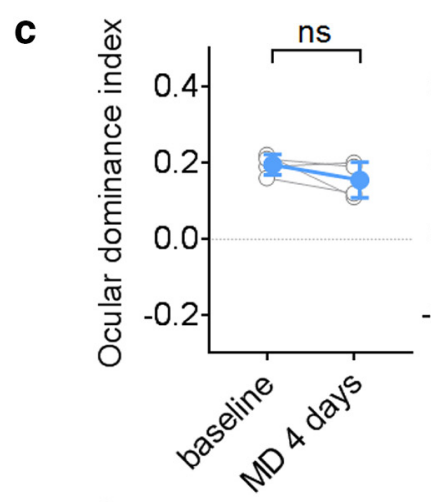

c

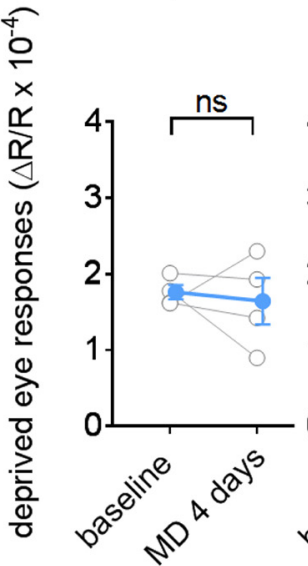

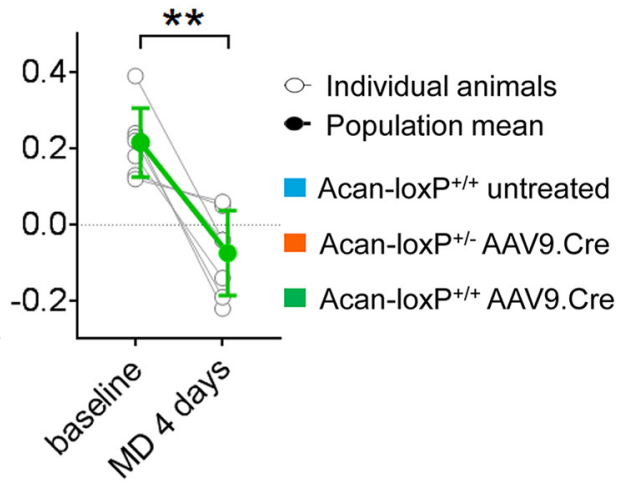

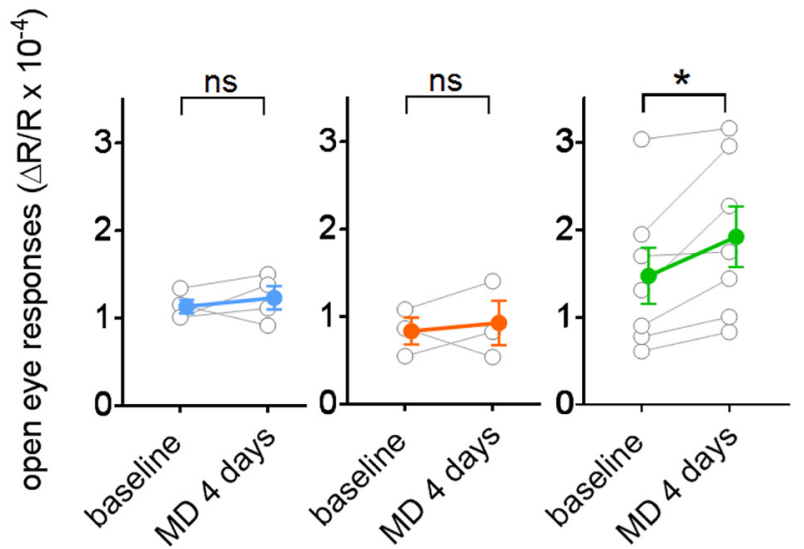

Figure 4. Local removal of Acan in V1 reactivates juvenile OD plasticity. $\boldsymbol{a}$, Injection of the retrograde tracer cholera toxin subunit B (CtxB) conjugated to different fluorophores, at two closely aligned sites in V1 of nontargeted Acan-loxP ${ }^{+/+}$mice. Representative wide-field image from V1 (top) and confocal images from the dorsal part of the lateral geniculate nucleus (dLGN) of the thalamus. Labeled projections stem from adjacent patches of neurons in dLGN, indicating a normal connectivity pattern with retinotopic organization. Sections were counterstained with DAPI to distinguish brain areas, and data were reproduced in two mice. $\boldsymbol{b}$, Experimental time line for optical imaging of intrinsic signals before and after MD of adult mice. $\boldsymbol{c}, 0 \mathrm{DI}$ calculated for responses to stimulating the ipsilateral and contralateral eye separately, before and after $4 \mathrm{~d}$ of MD. Positive ODI indicates contralateral bias while negative ODI indicates ipsilateral bias. Four days of MD did not affect ocular dominance in noninjected Acan-loxP ${ }^{+/+}$mice $\left(p=0.21\right.$, paired $t$ test, $n=4$ mice) or in heterozygous AAV9. (re-injected Acan-loxP ${ }^{+/-}$mice $(p=0.32$, paired $t$ test, $n=3$ mice $)$. In AAV9.Cre-injected Acan-loxP ${ }^{+/+}$mice, MD caused a significant shift in activation toward the open eye ( $p=0.003$, paired $t$ test, $n=7$ mice). $\boldsymbol{d}$, Stimulus-evoked responses of intrinsic signals through the open or closed eye before and after $4 \mathrm{~d}$ of MD. The MD in AAV9. Cre injected Acan-loxP ${ }^{+/+}$caused both increased responses to ipsilateral stimulation $(p=0.02$, paired $t$ test, $n=7$ mice) and reduced responses to contralateral stimulation ( $p=0.009$, paired test, $n=7$ mice), while no effect was observed in controls. Acan-lox $P^{+/+}:$deprived eye responses, $p=0.73$ (Wilcoxon signed rank test); open eye responses, $p=0.48$ (paired $t$ test); Acan-loxP ${ }^{+/-}$AAV9. (re injected: deprived eye responses, $p=0.46$ (paired $t$ test); open eye responses, $p=0.70$ (paired $t$ test) ${ }^{*} p<$ $0.05,{ }^{* *} p<0.01$. Open circles and gray lines indicates individual animals, solid circles and thick lines indicate population mean \pm SD.

adult plasticity or instead reinstated juvenile plasticity, the responses to stimulation of each eye before and after MD were investigated. We did not see the adult OD plasticity pattern, characterized by the strengthening of ipsilateral input to V1. Instead, the shift in OD was driven both by a potentiation of ipsilateral responses and a reduction in contralateral responses, indicating plasticity mechanisms similar to juvenile animals (Fig. $4 d$ ). No significant effects were observed in noninjected Acan-loxP ${ }^{+/+}$ mice or AAV9.Cre-injected Acan-loxP ${ }^{+/-}$mice (Fig. 4d).

Several interventions affecting PNNs have effects on learning and memory (Gogolla et al., 2009; Carulli et al., 2010; Romberg et al., 2013). The effect of brain-wide knockdown of aggrecan in learning and memory behavior was tested in the spontaneous object recognition paradigm (Romberg et al., 2013). In this par- 
a

\begin{tabular}{|c|c|c|c|c|c|c|}
\hline Timepoint & 3 hour 1 & \multicolumn{2}{|c|}{24 hour 1} & 3 hour 2 & \multicolumn{2}{|c|}{24 hour 2} \\
\hline Habituation & $\begin{array}{c}\text { Choice } \\
\square\end{array}$ & Sample & $\begin{array}{c}\text { Choice } \\
\quad\end{array}$ & $\begin{array}{c}\text { Choice } \\
\quad\end{array}$ & $\begin{array}{c}\text { Sample } \\
\text {, }\end{array}$ & Choice \\
\hline $\operatorname{Day}(\mathrm{s}) 1-2$ & 3 & 5 & 6 & 8 & 10 & 11 \\
\hline
\end{tabular}

b
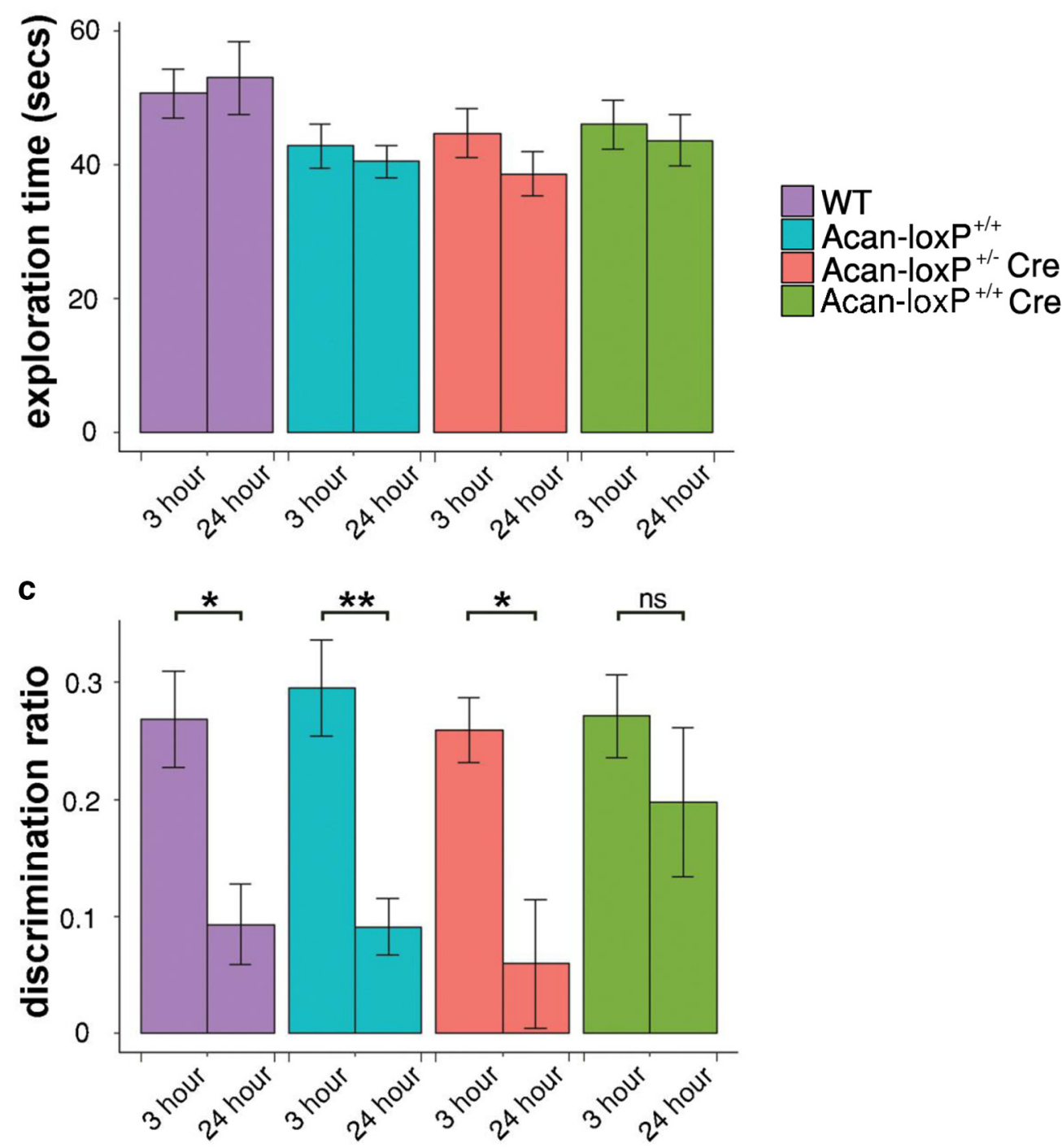

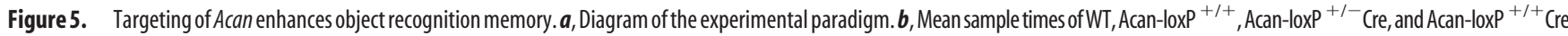
for 3 and $24 \mathrm{~h}$ sample phases during spontaneous object recognition testing. All animals participated well in the test with the average exploration time $\sim 40 \mathrm{~s}$. c, Mean object recognition scores following 3 and $24 \mathrm{~h}$ delays. A significant decrease in object recognition ability was detected in the WT, Acan-loxP ${ }^{+/+}$, and Acan-loxP ${ }^{+/-}$Cre groups following a 24 delay between sample and choice phases, while Acan-loxP ${ }^{+/+}$Cre did not. ${ }^{* *} p<0.01,{ }^{*} p<0.05$. ns, Not significant.

adigm, depicted in Figure $5 a$, animals (more than seven per group) identify novel from familiar objects (choice phase) following a delay from familiar object presentation (sample phase). Animals were tested after 3 and $24 \mathrm{~h}$ delays, at which times ChABC-treated and Crtll knock-out animals show enhanced memory retention (Romberg et al., 2013). Following the $3 \mathrm{~h}$ delay between sample and choice phases, all groups displayed a good ability to recognize the novel object from among familiar objects (discrimination ratio $>0.25$ ). At $24 \mathrm{~h}$ of the sample phase, the

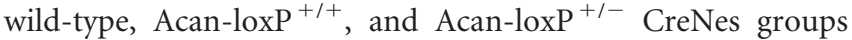
(Fig. 5c) showed little remaining memory. Remarkably, the object recognition memory in the Acan-loxP ${ }^{+/+}$CreNes group was still sustained at $24 \mathrm{~h}$ after object exposure (Fig. $5 c$ ), indicating a stronger recognition memory in mice lacking aggrecan. These results are very similar to those obtained after ChABC treatment and in Crtll knockouts, suggesting that the Acan knockout affects memory through effects on glycan chains in PNNs. Although heterozygous Acan-loxP ${ }^{+/-}$CreNes mice have reduced PNN in- 
Table 6. Statistical analysis spontaneous object recognition task

\begin{tabular}{|c|c|c|c|c|}
\hline & Sum squared error & $d f$ & Fvalue & $\operatorname{Pr}(>F)$ \\
\hline \multicolumn{5}{|c|}{ ANOVA table (Type III tests) } \\
\hline Intercept & 1.10135 & 1 & 74.7174 & $3.939 \mathrm{e}-12^{* * *}$ \\
\hline Time point & 0.45081 & 1 & 30.5840 & $7.362 \mathrm{e}-07^{* * *}$ \\
\hline Residuals & 0.88441 & 60 & & \\
\hline \multicolumn{5}{|c|}{ Welch two-sample $t$ test—SOR time point } \\
\hline 3 vs $24 \mathrm{~h}$ & $t$ & df & $p$ value & Mean of $x$, mean of $y$ \\
\hline WT & 2.5638 & 11.555 & $0.02547^{*}$ & $0.291830,0.127394$ \\
\hline Homo & 4.326 & 11.201 & $0.001154^{* *}$ & $0.27991577,0.07462545$ \\
\hline Het & 2.7797 & 12.071 & $0.01658^{*}$ & $0.26169284,0.08900274$ \\
\hline HomoCre & 0.92565 & 9.832 & 0.3768 & $0.2668251,0.2013353$ \\
\hline
\end{tabular}

${ }^{*} p=0.05 ;{ }^{* *} p=0.01 ;{ }^{* * *} p=0.001$.

tensity and altered PV expression, alterations in their behavior were not detected.

\section{Discussion}

It has been suggested that aggrecan-containing PNNs play an essential role in the regulation of brain plasticity. However, the hypothesis has been difficult to test directly due to the technical limitations such as the off-target effects of the PNN-degrading enzyme ChABC and the dependence on intact aggrecan for cartilage formation. In the current work, we established a conditional knock-out model for aggrecan and demonstrate that aggrecan is indeed required for the aggregation of PNNs, and that its removal reopens juvenile plasticity in visual cortex and affects memory processing. This work reveals that aggrecan is essential for PNN formation in vivo, and the specific loss of PNNs increase adult brain plasticity.

PNNs probably control synaptic plasticity and dynamics through several mechanisms. Most of these depend on the actions of the sulfated CSPG glycosaminoglycan chains attached to the several CSPGs that populate PNNs (Sorg et al., 2016); selective binding and facilitated internalization of the homeobox transcription factor OTX2, which affects the maturation of $\mathrm{PV}^{+}$ interneurons (Beurdeley et al., 2012); binding and presentation of chemorepulsive semaphorin3A (Dick et al., 2013); and the regulation of AMPA receptor mobility (Frischknecht et al., 2009). These mechanisms are based on the distinctive PNN structure, with the tight cross-linking structures of matrix proteins, CS, and hyaluronic acid polysaccharides forming a condensed compact matrix surrounding the cell soma and proximal dendrites, and the ability of the negatively charged sulfation patterns of the CS to allow specific interactions with positively charged domains in PNN-interacting proteins. Indeed, the ratio of 4- and 6-sulfated CS influences neuronal plasticity (Miyata et al., 2012). Our data suggest that aggrecan plays a key role for the PNN structure, possibly through the large number of glycan chains that it carries, but clearly by affecting formation. Removal of aggrecan abolishes the aggregation of PNNs, and essentially also the incorporation of other ECM components into the structure (Figs. 1, 3). Aggrecan is an efficient cross-linker interacting with hyaluronic acid and link protein by its N-terminal G1 domain and the extensively CS GAG-modified central domain (Morawski et al., 2012). The three globular domains, G1, G2, and G3, interact with several matrix molecules aiding cross-linking, which could explain the failure of other components to aggregate in its absence. The increased plasticity after PNN removal could also be a direct consequence of neuronal activity changes in $\mathrm{PV}^{+}$cells. This has been shown to be an important factor in the regulation of CP plasticity (Hensch, 2004), and previous work has shown that PNN removal reduces the activity of $\mathrm{PV}^{+}$neurons (Balmer, 2016; Lensjø et al., 2017).
The changes in activity could be a result of reduced ion buffering, changes to the synaptic inputs onto $\mathrm{PV}^{+}$cells, alteration within the PV cells due to changed interaction with external molecular cues, or a combination of these.

The condensation of PNNs in sensory cortices correlates with the closure of periods of heightened neuronal plasticity in sensory systems. Our results show that monocular deprivation induces a strong and rapid change in cortical activation in $\mathrm{V} 1$ after just $4 \mathrm{~d}$ of MD. The time frame of this shift is faster than what has been observed in CP aged mice (Sato and Stryker, 2008) but is in line with previous work on adult mice with induced plasticity (Fu et al., 2015). While monocular deprivation in adults normally affects only responses to ipsilateral eye stimulation, we observed changes in responsiveness to both contralateral and ipsilateral inputs to V1 (Fig. 4), similar to how this shift occurs in CP aged animals. This finding is supported by our recent work, which showed that brief MD in adult rats following enzymatic degradation of PNNs caused a similar effect on recorded single units in $\mathrm{V} 1$, in both hemispheres relative to the deprived eye (Lensjø et al., 2017). These effects differ from other manipulations to activate adult cortical plasticity such as Lynx1 deletion (Morishita et al., 2010), which arises as a result of potentiated responses to ipsilateral stimuli. Together, these suggest that the PNN is a determinant factor in the closure of the CPs in juvenile development, through its effect on $\mathrm{PV}^{+}$neurons and action as a structural barrier. The removal of aggrecan collapses the PNN structure and leads to a persistent state of juvenile-like plasticity.

Our data also show that populations of $\mathrm{PV}^{+}$interneurons in both homozygous and heterozygous Acan-loxP ${ }^{+/+}$-CreNes mice are shifted to a state where they express less PV (Fig. 2). Others have suggested that the level of PV in $\mathrm{PV}^{+}$interneurons determine whether the network is in a state of high or low plasticity (Donato et al., 2013) through a mechanism involving gene expression of PV and the GABA-synthesizing enzyme GAD67 and regulation of the activity of the neurons through changes in dendritic synaptic contacts. Decreased PV expression and synapses are associated with hippocampal learning, while fear conditioning leads to a high-PV state. PV-+ neuron-controlled shifts in network state are suggested as an integrated mechanism of learning and memory acquisition. ChABC treatment to degrade PNNs shifted the network to a low-PV state, indicating that the glycans on CSPGs are a key component in controlling PV interneuron influence on network state. Mounting evidence from other brain structures supports a broader role for PNNs where they affect behavior, memory, and learning processes. We show that PNN removal by aggrecan knockout improves object recognition memory (Fig. 5), in line with previous work (Romberg et al., 2013). Recently, aggrecan and PNNs have been implied in vari- 
ous psychiatric disorders (Pantazopoulos et al., 2015) and in the progression of neurodegenerative diseases (Suttkus et al., 2016). Subtle differences in matrix and PNN structure might impact the balance among a resilient, a susceptible, and a vulnerable state.

In the current study, the Acan-loxP mouse line has established a role for this CSPG in the control of plasticity in visual cortex and in memory. Aggrecan is the key component for assembling and sustaining the PNNs structure and function in the adult brain and may play a central role in regulating adult brain plasticity.

\section{References}

Balmer TS (2016) Perineuronal nets enhance the excitability of fast-spiking neurons. eNeuro 3:ENEURO.0112-16.2016. CrossRef Medline

Balmer TS, Carels VM, Frisch JL, Nick TA (2009) Modulation of perineuronal nets and parvalbumin with developmental song learning. J Neurosci 29:12878-12885. CrossRef Medline

Beurdeley M, Spatazza J, Lee HH, Sugiyama S, Bernard C, Di Nardo AA, Hensch TK, Prochiantz A (2012) Otx2 binding to perineuronal nets persistently regulates plasticity in the mature visual cortex. J Neurosci 32:9429-9437. CrossRef Medline

Carulli D, Pizzorusso T, Kwok JC, Putignano E, Poli A, Forostyak S, Andrews MR, Deepa SS, Glant TT, Fawcett JW (2010) Animals lacking link protein have attenuated perineuronal nets and persistent plasticity. Brain 133:2331-2347. CrossRef Medline

Deepa SS, Carulli D, Galtrey C, Rhodes K, Fukuda J, Mikami T, Sugahara K, Fawcett JW (2006) Composition of perineuronal net extracellular matrix in rat brain: a different disaccharide composition for the netassociated proteoglycans. J Biol Chem 281:17789-17800. CrossRef Medline

Dick G, Tan CL, Alves JN, Ehlert EM, Miller GM, Hsieh-Wilson LC, Sugahara K, Oosterhof A, van Kuppevelt TH, Verhaagen J, Fawcett JW, Kwok JC (2013) Semaphorin 3A binds to the perineuronal nets via chondroitin sulfate type E motifs in rodent brains. J Biol Chem 288:27384-27395. CrossRef Medline

Donato F, Rompani SB, Caroni P (2013) Parvalbumin-expressing basketcell network plasticity induced by experience regulates adult learning. Nature 504:272-276. CrossRef Medline

Frischknecht R, Heine M, Perrais D, Seidenbecher CI, Choquet D, Gundelfinger ED (2009) Brain extracellular matrix affects AMPA receptor lateral mobility and short-term synaptic plasticity. Nat Neurosci 12:897904. CrossRef Medline

Fu Y, Kaneko M, Tang Y, Alvarez-Buylla A, Stryker MP (2015) A cortical disinhibitory circuit for enhancing adult plasticity. Elife 4:e05558. CrossRef Medline

Giamanco KA, Morawski M, Matthews RT (2010) Perineuronal net formation and structure in aggrecan knockout mice. Neuroscience 170:13141327. CrossRef Medline

Gogolla N, Caroni P, Lüthi A, Herry C (2009) Perineuronal nets protect fear memories from erasure. Science 325:1258-1261. CrossRef Medline

Härtig W, Brauer K, Bigl V, Brückner G (1994) Chondroitin sulfate proteoglycan-immunoreactivity of lectin-labeled perineuronal nets around parvalbumin-containing neurons. Brain Res 635:307-311. CrossRef Medline

Hensch TK (2004) Critical period regulation. Annu Rev Neurosci 27:549579. CrossRef Medline

Kalatsky VA, Stryker MP (2003) New paradigm for optical imaging: temporally encoded maps of intrinsic signal. Neuron 38:529-545. CrossRef Medline

Kaneko M, Stellwagen D, Malenka RC, Stryker MP (2008) Tumor necrosis factor-alpha mediates one component of competitive, experiencedependent plasticity in developing visual cortex. Neuron 58:673-680. CrossRef Medline

Kwok JC, Carulli D, Fawcett JW (2010) In vitro modeling of perineuronal nets: hyaluronan synthase and link protein are necessary for their formation and integrity. J Neurochem 114:1447-1459. CrossRef Medline

Kwok JC, Dick G, Wang D, Fawcett JW (2011) Extracellular matrix and perineuronal nets in CNS repair. Dev Neurobiol 71:1073-1089. CrossRef Medline

Lensjø KK, Lepperød ME, Dick G, Hafting T, Fyhn M (2017) Removal of perineuronal nets unlocks juvenile plasticity through network mechanisms of decreased inhibition and increased gamma activity. J Neurosci 37:1269-1283. CrossRef Medline

Matthews RT, Kelly GM, Zerillo CA, Gray G, Tiemeyer M, Hockfield S (2002) Aggrecan glycoforms contribute to the molecular heterogeneity of perineuronal nets. J Neurosci 22:7536-7547. CrossRef Medline

Miyata S, Kitagawa H (2016) Chondroitin 6-sulfation regulates perineuronal net formation by controlling the stability of aggrecan. Neural Plast 2016:1305801. CrossRef Medline

Miyata S, Komatsu Y, Yoshimura Y, Taya C, Kitagawa H (2012) Persistent cortical plasticity by upregulation of chondroitin 6-sulfation. Nat Neurosci 15:414-422, S1-2. CrossRef Medline

Morawski M, Brückner G, Arendt T, Matthews RT (2012) Aggrecan: beyond cartilage and into the brain. Int J Biochem Cell Biol 44:690-693. CrossRef Medline

Morishita H, Miwa JM, Heintz N, Hensch TK (2010) Lynx1, a cholinergic brake, limits plasticity in adult visual cortex. Science 330:1238-1240. CrossRef Medline

Pantazopoulos H, Markota M, Jaquet F, Ghosh D, Wallin A, Santos A, Caterson B, Berretta S (2015) Aggrecan and chondroitin-6-sulfate abnormalities in schizophrenia and bipolar disorder: a postmortem study on the amygdala. Transl Psychiatry 5:e496. CrossRef Medline

Pau G, Fuchs F, Sklyar O, Boutros M, Huber W (2010) EBImage-an R package for image processing with applications to cellular phenotypes. Bioinformatics 26:979-981. CrossRef Medline

Pettitt SJ, Liang Q, Rairdan XY, Moran JL, Prosser HM, Beier DR, Lloyd KC Bradley A, Skarnes WC (2009) Agouti C57BL/6N embryonic stem cells for mouse genetic resources. Nat Methods 6:493-495. CrossRef Medline

Pizzorusso T, Medini P, Berardi N, Chierzi S, Fawcett JW, Maffei L (2002) Reactivation of ocular dominance plasticity in the adult visual cortex. Science 298:1248-1251. CrossRef Medline

Ranson A, Cheetham CE, Fox K, Sengpiel F (2012) Homeostatic plasticity mechanisms are required for juvenile, but not adult, ocular dominance plasticity. Proc Natl Acad Sci U S A 109:1311-1316. CrossRef Medline

Rittenhouse E, Dunn LC, Cookingham J, Calo C, Spiegelman M, Dooher GB, Bennett D (1978) Cartilage matrix deficiency (CMD): a new autosomal recessive lethal mutation in the mouse. J Embryol Exp Morphol 43:71-84. Medline

Romberg C, Yang S, Melani R, Andrews MR, Horner AE, Spillantini MG, Bussey TJ, Fawcett JW, Pizzorusso T, Saksida LM (2013) Depletion of perineuronal nets enhances recognition memory and long-term depression in the perirhinal cortex. J Neurosci 33:7057-7065. CrossRef Medline

Sato M, Stryker MP (2008) Distinctive features of adult ocular dominance plasticity. J Neurosci 28:10278-10286. CrossRef Medline

Sawtell NB, Frenkel MY, Philpot BD, Nakazawa K, Tonegawa S, Bear MF (2003) NMDA receptor-dependent ocular dominance plasticity in adult visual cortex. Neuron 38:977-985. CrossRef Medline

Skarnes WC, Rosen B, West AP, Koutsourakis M, Bushell W, Iyer V, Mujica AO, Thomas M, Harrow J, Cox T, Jackson D, Severin J, Biggs P, Fu J, Nefedov M, de Jong PJ, Stewart AF, Bradley A (2011) A conditional knockout resource for the genome-wide study of mouse gene function. Nature 474:337-342. CrossRef Medline

Sorg BA, Berretta S, Blacktop JM, Fawcett JW, Kitagawa H, Kwok JC, Miquel M (2016) Casting a wide net: role of perineuronal nets in neural plasticity. J Neurosci 36:11459-11468. CrossRef Medline

Suttkus A, Morawski M, Arendt T (2016) Protective properties of neural extracellular matrix. Mol Neurobiol 53:73-82. CrossRef Medline

Tronche F, Kellendonk C, Kretz O, Gass P, Anlag K, Orban PC, Bock R, Klein R, Schütz G (1999) Disruption of the glucocorticoid receptor gene in the nervous system results in reduced anxiety. Nat Genet 23:99-103. CrossRef Medline

Yamada J, Ohgomori T, Jinno S (2015) Perineuronal nets affect parvalbumin expression in GABAergic neurons of the mouse hippocampus. Eur J Neurosci 41:368-378. CrossRef Medline 